\title{
Cyclocreatine treatment improves cognition in mice with creatine transporter deficiency
}

\author{
Yuko Kurosawa, ${ }^{1}$ Ton J. DeGrauw, ${ }^{2}$ Diana M. Lindquist, ${ }^{3}$ Victor M. Blanco, ${ }^{4}$ Gail J. Pyne-Geithman, ${ }^{5}$ \\ Takiko Daikoku, ${ }^{6}$ James B. Chambers, ${ }^{7}$ Stephen C. Benoit, ${ }^{7}$ and Joseph F. Clark ${ }^{1,2}$ \\ 1Department of Neurology, University of Cincinnati, Cincinnati, Ohio, USA. 2Division of Neurology and 3Department of Radiology and Imaging Research Center, \\ Cincinnati Children's Hospital Medical Center, Cincinnati, Ohio, USA. ${ }^{4}$ Department of Emergency Medicine and ${ }^{5}$ Department of Neurosurgery, \\ University of Cincinnati, Cincinnati, Ohio, USA. ${ }^{6}$ Division of Reproductive Science, Cincinnati Children's Hospital Medical Center, \\ Cincinnati, Ohio, USA. ${ }^{7 D e p a r t m e n t ~ o f ~ P s y c h i a t r y ~ a n d ~ B e h a v i o r ~ N e u r o s c i e n c e, ~ U n i v e r s i t y ~ o f ~ C i n c i n n a t i, ~ C i n c i n n a t i, ~ O h i o, ~ U S A . ~}$
}

\begin{abstract}
The second-largest cause of $X$-linked mental retardation is a deficiency in creatine transporter (CRT; encoded by $S L C 6 A 8$ ), which leads to speech and language disorders with severe cognitive impairment. This syndrome, caused by the absence of creatine in the brain, is currently untreatable because CRT is required for creatine entry into brain cells. Here, we developed a brain-specific Slc6a8 knockout mouse $\left(S l c 6 a 8^{-/ y}\right)$ as an animal model of human CRT deficiency in order to explore potential therapies for this syndrome. The phenotype of the $S l c 6 a 8^{-/ y}$ mouse was comparable to that of human patients. We successfully treated the Slc6a8 $8^{-/ y}$ mice with the creatine analog cyclocreatine. Brain cyclocreatine and cyclocreatine phosphate were detected after 9 weeks of cyclocreatine treatment in $S l c 6 a 8^{-/ y}$ mice, in contrast to the same mice treated with creatine or placebo. Cyclocreatine-treated $S l c 6 a 8^{-/ y}$ mice also exhibited a profound improvement in cognitive abilities, as seen with novel object recognition as well as spatial learning and memory tests. Thus, cyclocreatine appears promising as a potential therapy for CRT deficiency.
\end{abstract}

\section{Introduction}

Creatine transporter (CRT; encoded by SLC6A8; geneID 6535) transports creatine with high specificity into cells via secondary active transport, using the $\mathrm{Na}^{+}$gradient to drive the transport against creatine's concentration gradient. Creatine and its phosphorylated form, phosphocreatine, are used as an energy reservoir by buffering ATP concentration via the creatine kinase (CK) reaction (1). This high-energy phosphate-buffering system is essential to maintain ATP levels. CK and CRT are coexpressed in many tissues with a dynamic and/or fluctuating energy demand. In the CNS, the creatine/phosphocreatine/CK system plays an important role in neurotransmitter release, membrane potential maintenance, $\mathrm{Ca}^{2+}$ homeostasis, and/or ion gradient restoration (1-3). SLC6A8, a member of the solute carrier 6 family, is expressed in many tissues, such as CNS, heart, and skeletal muscle (4), and is highly specific for creatine (5-7). Interestingly, the CNS is the main organ affected by creatine deficiency syndromes, including CRT deficiency. There appears to be normal cardiac function and normal creatine levels in the muscles of patients with CRT deficiency (8).

Of the 3 creatine deficiency syndromes, L-arginine:glycine amidinotransferase (AGAT) deficiency and guanidinoacetate N-methyltransferase (GAMT) deficiency are caused by defects in the enzymes that synthesize creatine, whereas CRT deficiency results from a defect in CRT caused by SLC6A8 deficiency, such that creatine cannot enter the brain's cells. In patients, creatine deficiency syndromes have several common clinical manifestations, including cognitive dysfunction with mental retardation, poor language skills, and autism spectrum disorders (9-15). Proton magnetic resonance spectroscopy (MRS) of affected patients shows an absence or dramatic diminution of the creatine peak, with relatively normal levels of $\mathrm{N}$-acetyl aspartate $(9,16,17)$.

Conflict of interest: The authors have declared that no conflict of interest exists. Citation for this article: J Clin Invest. 2012;122(8):2837-2846. doi:10.1172/JCI59373.
Whereas AGAT and GAMT deficiencies have been identified in about 100 patients worldwide, CRT deficiency is described as the second-most common cause of X-linked mental retardation, with an estimated 42,000 individuals affected in the US and approximately 1 million worldwide (17-20). Because SLC6A8 is located on human chromosome $\mathrm{Xq} 28$, mutations in this gene result in a more severe syndrome in males than in female carriers. Patients with AGAT deficiency or GAMT deficiency have been successfully treated with creatine supplementation, which reverses symptoms, as well as other supplements, which manage buildup of intermediate metabolites $(13-15,21,22)$; however, patients with CRT deficiency are not successfully treated with creatine supplementation $(10,16,23-25)$. Creatine is found in blood and cerebrospinal fluid (CSF), but is not able to enter brain cells - the cell membranes are an effective barrier to creatine transport.

Some previous studies suggest that the rodent brain has the enzymes to synthesize creatine $(4,5,26,27)$. However, it appears that the synthesis system does not work in mice or humans in vivo, because no detectable brain creatine was observed in the Slc6a8 whole-body knockout mouse (28) or in human patients $(9,16,17)$, as assessed by biochemical assays or MRS.

Normal brain function might primarily depend on its ability to transport creatine into neurons, as suggested by the presence of creatine in the CSF of patients with CRT deficiency. Despite its presence in the CSF, however, patients' brain creatine levels are markedly reduced or not detectable when measured by ${ }^{1} \mathrm{H}$-MRS. Yet a lack of MRS signal does not prove that creatine is absent; it could be present at levels below the detection limit. SLC6A8 is highly expressed in neurons and oligodendrocytes, but not in astrocytes, and is present in microcapillary endothelial cells (MCECs), which form part of the blood-brain-barrier (BBB) (5). An additional part of the BBB is a barrier between the periphery and the CNS, formed by astrocytic end-feet around MCECs, which regulate water and metabolite exchange. Passive creatine diffusion into brain cells - against its concentration gradient - 


\section{Cyclocreatine}<smiles>NC1=NCCN1CC(=O)O</smiles>

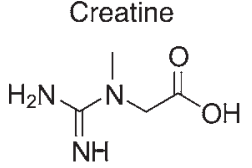

\section{Figure 1}

Chemical structural formulas of cyclocreatine and creatine. Cyclocreatine is a kinetically similar analog of creatine that is phosphorylated and dephosphorylated by mitochondrial and cytosolic CKs. As a small, relatively planar molecule, cyclocreatine has the chemical characteristics to cross membranes.

is not expected to generate significant brain creatine levels, and this is supported by data in patients.

Currently, there is no approved treatment for patients with CRT deficiency; treatment strategies are palliative for managing seizure and related sequelae. In order to identify a strategy for treatment that focuses on the cognitive deficiencies, we needed a valid animal model with the phenotype of the human disease. Here, we generated a brain-specific Slc6a8 knockout mouse (referred to herein as $\operatorname{Slc} 6 a 8^{-/ y}$ ) with specific knockout of target areas of cortex and hippocampus - the predominant areas of the brain for cognition and memory - and treated those mice with the creatine analog cyclocreatine (1-carboxymethyl-2-iminoimidazolidine).

Cyclocreatine is a nearly planar creatine analog (Figure 1) with a maximum kinetic velocity approaching that of creatine itself (29). Because its planar characteristics aid in passive transport across membranes, cyclocreatine might therefore be useful in the treatment of CRT deficiency. Moreover, cyclocreatine is phosphorylated and dephosphorylated by mitochondrial and cytosolic CK (30). It has already been demonstrated that cyclocreatine phosphate can indeed function as a phosphagen in mouse brain in vivo (31). Cyclocreatine was given to humans when it was investigated as a chemotherapeutic adjunct under an investigational new drug phase I safety study; thus, toxicology and cGMP data are known $(32,33)$. Here, we assessed the ability of cyclocreatine to treat Slc6a $8^{-1 y}$ mice. We hypothesized that cyclocreatine would cross the $\mathrm{BBB}$ and pass through brain cell membranes, improving cognitive function in treated mice.

Our results showed that Slc6a8 was efficiently deleted in Slc6a8- $y$ mouse brains, and creatine content in these brains was somewhat consistent with that seen in human patients. Slc6a8- $/ y$ mice had impaired cognitive function, but normal balance and musculoskeletal control systems, also similar to human patients. Cognitive abilities were improved after 9 weeks of cyclocreatine treatment compared with $S l c 6 a 8^{f / y}$ control littermates, with cyclocreatine and cyclocreatine phosphate seen in the mouse brain. Our results confirmed that in mice, cognitive deficiencies were caused by a lack of CRT in the brain, and that this cognitive deficit could be reversed by 9 weeks of treatment with cyclocreatine.

\section{Results}

Creatine concentrations in brains and other organs. The knockout strategy is outlined in Figure 2A. We found substantially decreased levels of creatine in the brains of Slc $6 a 8^{-/ y}$ mice compared with littermate Slc6a $8^{f / y}$ controls $(2.8 \pm 0.11$ versus $11.2 \pm 0.74 \mathrm{mmol} / \mathrm{kg}$ wet wt; $P \leq 0.001$; Table 1 ), a diminution close to that measured in patients by ${ }^{1} \mathrm{H}-\mathrm{MRS}$. The relative reduction of brain creatine was similar to the reduced Slc6a 8 mRNA expression in Slc6a8 $8^{-/ y}$ mice (Figure 2B and Supplemental Figure 1; supplemental material available online with this article; doi:10.1172/JCI59373DS1). Furthermore, there were no differences in any of the tissues studied, excepting a statistically significant increase in the amount of creatine in the urine $\left(\operatorname{Slc6a8^{-1y}}, 10.2 \pm 2.57 \mathrm{mM}\right.$; Slc6a $8^{f l y}, 4.0 \pm 0.66 \mathrm{mM}$; $P \leq 0.05$; Table 1).

Body morphometry. Although no significant difference in body weight or percent lean body mass was observed in Slc6a8-/y compared with $S l c 6 a 8^{f / y}$ mice before or after treatment, percent body fat was significantly lower at baseline (Slc6a8 $8^{-/ y}, 15.8 \% \pm 1.3 \%$; Slc6a8 $\left.8^{f / y}, 19.8 \% \pm 1.4 \% ; P \leq 0.05\right)$, a trend that was still seen after treatment (Supplemental Figure 2, A-C). This may be due to increased activity in $S l c 6 a 8^{-/ y}$ compared with Slc6a8fl/y mice (Supplemental Figure 2D). Treatment with cyclocreatine, creatine, or placebo did not significantly change morphometric parameters in Slc6a8 $8^{-/ y}$ or $S l c 6 a 8^{f / y}$ mice.

Cyclocreatine. We observed successful cyclocreatine entry into the brains of all mice treated with cyclocreatine for 9 weeks, with higher levels in Slc6a8fly than in Slc6a8 $8^{-/ y}$ brains (3.1 \pm 0.34 vs. $1.7 \pm 0.2 \mathrm{mmol} / \mathrm{kg}$ wet wt; $P \leq 0.001$; Figure 3 ). Brain cyclocreatine was also observed by chemical analysis as well as by nuclear MRS (Figure 4 and Supplemental Figure 3). We also found cyclocreatine in mouse hair (Slc6a $8^{f l y}, 34.8 \pm 3.7 \mathrm{mmol} / \mathrm{kg}$ dry wt; Slc6a8- $/ y$, $39.9 \pm 6.7 \mathrm{mmol} / \mathrm{kg}$ dry wt; Supplemental Figure 4) and claws (data not shown). There were no deaths or overt health problems observed in any of the groups studied.

${ }^{31} \mathrm{P}-\mathrm{MRS}$. We observed a decrease in ${ }^{31} \mathrm{P}$ phosphocreatine in Slc6a $8^{-1 y}$ versus control Slc6a $8^{f / y}$ brains; however, there was a profound lack of phosphocreatine peak, with no detectable inorganic phosphate, in the former group (Supplemental Figure 3 and Figure 4, A and B). Treatment with cyclocreatine did result in metabolite changes (Figure 4B), and we observed a substantial peak corresponding to cyclocreatine phosphate (and/or phosphocreatine) in Slc6a8 ${ }^{-/ y}$ mice (Supplemental Figure 3). The peak positions of phosphocreatine and cyclocreatine phosphate are separated by less than $0.2 \mathrm{ppm}$ (34), which means that they cannot be resolved by in vivo nuclear MRS. Because our chemical analysis showed no significant change in creatine, we interpret this peak to represent cyclocreatine phosphate. The presumed cyclocreatine phosphate levels appeared comparable in Slc6a8 $8^{-1 y}$ and Slc6a8fly mice, which suggests that cyclocreatine is phosphorylated in the brains of these mice.

Spatial learning and memory. Spatial learning and memory are executive functions for mice, with consequences for environment familiarity and food finding; therefore, we used the established Morris water maze and radial arm maze tests to assess these cognitive functions. In the Morris water maze, Slc6a8 $8^{-1 y}$ mice took significantly longer to find the hidden platform in the last 3 training trials than did Slc6a $8^{f / y}$ controls before treatment; 9 weeks of cyclocreatine treatment improved the performance of Slc6a8 $8^{-/ y}$ mice so that they were not significantly impaired compared with controls, whereas creatine or placebo did not significantly change Slc6a8-1y mouse performance (Figure $5 \mathrm{~A}$ ). The percentage of time spent in platform area during the probe trial also improved in Slc6a $8^{-1 y}$ mice after 9 weeks of cyclocreatine treatment (Figure 5B). The velocity of swimming in the platform area during the probe trial was not significantly different between groups before and after each treatment (Figure 5C), suggestive of normal motor function in the $S l c 6 a 8^{-1 y}$ group. We concluded that the impaired spatial learning and memory in Slc6a8 $-1 y$ mice was normalized by 9 weeks of cyclocreatine treatment. 
A
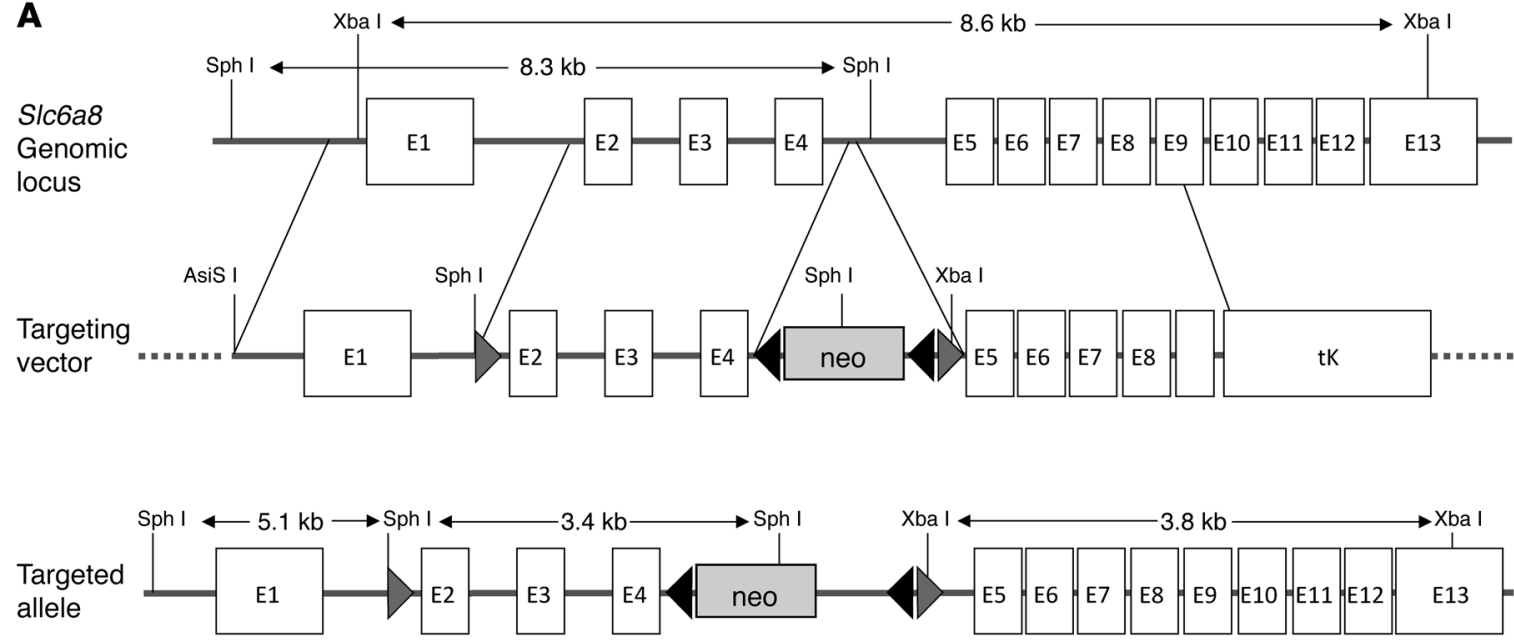

Following

flpsase expression

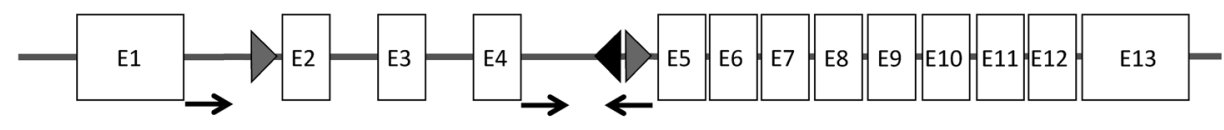

\section{Cre} recombinant allele
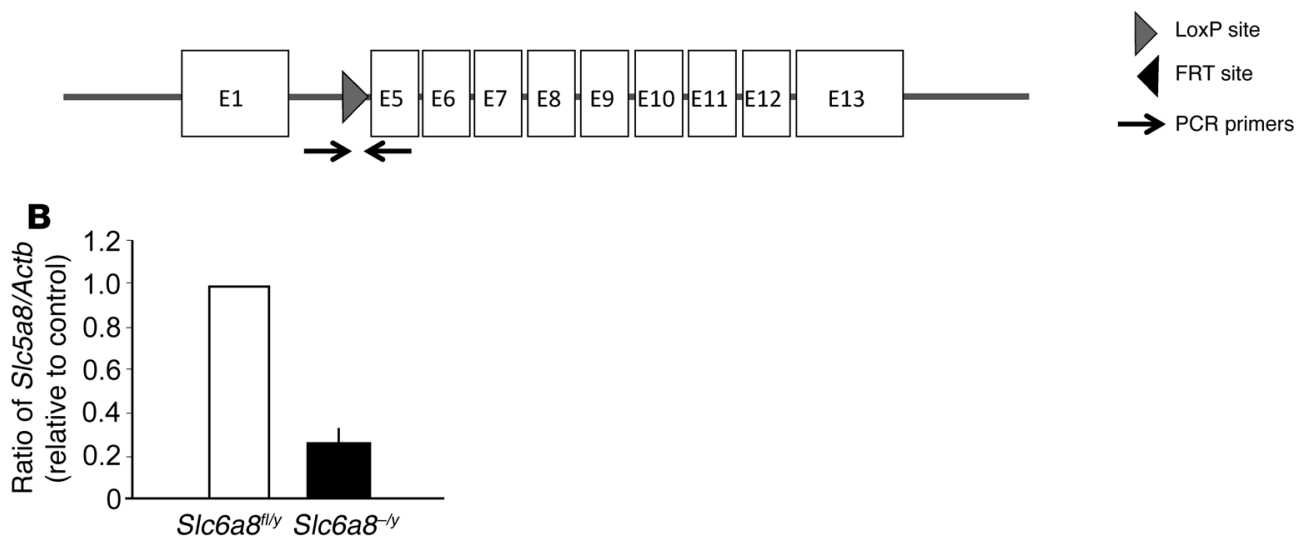

Figure 2

Brain-specific S/c6a8 knockout. (A) Strategy for recombination and deletion of S/c6a8. The structure of the wild-type S/c6a8 locus, the targeted locus after recombination in embryonic stem cells, and the floxed allele after Flp-mediated deletion of the neo cassette are shown. Cre expression results in deletion of exons 2-4 (E2-E4). Exons are denoted by boxes; neo, loxP sequences, and FRT sequences are denoted by triangles. (B) Quantitation of S/c6a8 mRNA levels. Band intensities in gel images were measured and corrected by the intensity of Actb.

In the radial arm maze task, Slc6a8 $8^{-/ y}$ mice consistently performed worse than their controls in all parameters measured at the baseline assessment (i.e., working memory error and reference memory error in both original baited arms and reversed baited arms; Supplemental Figure 5). In Slc6a $8^{f l / y}$ mice, working and reference errors decreased significantly in reversed baited arms compared with original baited arms $(P<0.001$ for both). However, no significant difference was seen in Slc6a8 $8^{-1 y}$ mice between original and reversed baited arms with respect to either error, suggestive of impairment.

Novel object recognition. Slc6a8 $8^{-/ y}$ mice showed significant impairment in the novel object recognition test that was normalized after 9 weeks of cyclocreatine treatment (Figure 6). Whereas the discrimination index was significantly lower in $S l c 6 a 8^{-/ y}$ than in Slc6a8fly mice before treatment $(-0.07 \pm 0.06$ versus $0.41 \pm 0.06$; $P \leq 0.001)$, cyclocreatine-treated Slc6a8 ${ }^{-/ y}$ mice showed a discrimi- nation index of $0.53 \pm 0.16$, not significantly different from that of littermate controls receiving the same treatment. The other treatments showed no significant change from pretreatment levels in the Slc6a8 ${ }^{-1 y}$ mice (creatine, $-0.03 \pm 0.06$; placebo, $0.05 \pm 0.13$ ).

Activity. Home cage activity increased in Slc6a8 $8^{-1 y}$ mice, which were significantly more active than $S l c 6 a 8^{f / y}$ controls, especially in the dark phase $(P<0.01$; Supplemental Figure 2D). The trend was still seen after cyclocreatine treatment $(P=0.06)$.

Motor function. All motor function parameters - duration to fall from a rotarod with maximal speed, latency to fall in the hanging wire test, and time taken to cross a $50-\mathrm{cm}$-long beam - were essentially identical between $\operatorname{Slc} 6 a 8^{-/ y}$ and $S l c 6 a 8^{f / y}$ mice and were not significantly changed after cyclocreatine treatment (Supplemental Figure 6). Moreover, no missteps were observed with the beam walk test. 
Table 1

Creatine content

\begin{tabular}{|c|c|c|}
\hline & $\begin{array}{c}S / c 6 a 8^{f / / y} \\
(n=10)\end{array}$ & $\begin{array}{c}\text { SIc6a8-1y } \\
(n=9)\end{array}$ \\
\hline \multicolumn{3}{|l|}{ Brain } \\
\hline Subcortical (mmol/kg wet wt) & $12.3 \pm 1.01$ & $2.8 \pm 0.20^{A}$ \\
\hline Cortex (mmol/kg wet wt) & $11.2 \pm 0.74$ & $2.8 \pm 0.11^{A}$ \\
\hline \multicolumn{3}{|l|}{ Skeletal muscle } \\
\hline Gastrocnemius (mmol/kg wet wt) & $37.6 \pm 3.13$ & $38.8 \pm 2.92$ \\
\hline Soleus (mmol/kg wet wt) & $30.2 \pm 2.04$ & $29.9 \pm 2.24$ \\
\hline Heart (mmol/kg wet wt) & $13.5 \pm 0.70$ & $13.5 \pm 1.97$ \\
\hline Bladder (mmol/kg wet wt) & $6.1 \pm 0.33$ & $5.5 \pm 0.29$ \\
\hline Kidney (mmol/kg wet wt) & $1.1 \pm 0.04$ & $1.1 \pm 0.10$ \\
\hline Liver (mmol/kg wet wt) & $0.24 \pm 0.02$ & $0.27 \pm 0.02$ \\
\hline Lung (mmol/kg wet wt) & $0.55 \pm 0.04$ & $0.49 \pm 0.04$ \\
\hline Serum (mM) & $0.14 \pm 0.01$ & $0.12 \pm 0.004$ \\
\hline Urine (mM) & $4.0 \pm 0.66$ & $10.2 \pm 2.57^{B}$ \\
\hline
\end{tabular}

Values are mean $\pm \mathrm{SEM} .{ }^{A} P \leq 0.001,{ }^{\mathrm{B}} P<0.05$ vs. S/c6a8 ${ }^{\mathrm{fll}}$, 2 -tailed Student's $t$ test.

\section{Discussion}

In the present study, we validated our brain-specific CRT-knockout Slc6a8- $8^{-y}$ mouse model of CRT deficiency as being comparable to the human disease. We also reported the effective treatment of cognitive deficits in Slc6a8-1y mice with 9 weeks of therapy with the repurposed drug cyclocreatine. We propose a 2-part model in which creatine and phosphocreatine prove central to the energy metabolism and function of brain cells (Figure 7, A and B): the creatine transport mechanism is interrupted, leading to impaired energy metabolism along with impaired function.

At baseline, the phenotype in Slc6a8 $8^{-/ y}$ mice was pronounced for cognitive and executive function deficits, but normal for balance and musculoskeletal control systems. Creatine and phosphocreatine in the brain was significantly decreased, whereas creatine in skeletal muscle, heart, and serum was normal (Table 1). Unlike whole-body Slc6a8-knockout mice, in which body weight is normal and urine creatine is high $(9,11,8,35,36)$, we observed normal creatine in Slc6a8 $8^{-1 y}$ muscle, also modeling what is seen in patients. After 9 weeks of cyclocreatine treatment, cyclocreatine entered the brain and was phosphorylated, and the cognitive deficits of $\operatorname{Slc} 6 a 8^{-/ y}$ mice were normalized compared with
Slc6a $8^{f l y}$ mice. Creatine or placebo treatment did not show any cognitive or musculoskeletal benefits for Slc6a $8^{-/ y}$ mice. These data suggest that cyclocreatine is a potential therapeutic for patients with CRT deficiency.

Justification of the Slc6a8- $1 y$ mouse model. A mouse model that resembles the human condition is an important tool with which to validate cyclocreatine as a therapy for patients with CRT deficiency. We had previously reported whole-body Slc6a8-knockout mice using different Cre recombinase (CMV promoter; ref. 28); these had a very severe phenotype distinct from that of patients with CRT deficiency, including motor deficits (8). We felt that cyclocreatine treatment of the whole-body knockout might produce results in which it would be difficult to distinguish cognitive and motor benefits. Thus, we here generated brain-specific Slc6a8 $8^{-/ y}$ mice in order to focus on the cognitive and executive function deficiencies key to the patient pathology we sought to address. Slc $6 a 8^{-1 y}$ mice had a phenotype with markedly reduced levels of creatine in the brain, similar to what is seen in human patients (37), as well as impaired cognitive function, normal motor function, and normal creatine levels in skeletal muscles, heart, and serum. With the current model and the results reported therein, we believe that cyclocreatine treatment improves brain function independent of muscle effects and therefore should be considered as a viable treatment of human CRT deficiency. However, the data do not tell us whether cyclocreatine enters the brain cells by diffusion or through an alternate transport mechanism.

Biochemical phenotype and buman CRT deficiency. CRT deficiency was originally characterized as lacking creatine in the brain $(9,16)$; similarly, we reported here a substantial decrease in creatine in mice lacking CRT, as assessed by biochemical analysis (Table 1). After cyclocreatine treatment, Slc6a8 $/ y$ mouse brains showed substantial increases in cyclocreatine and cyclocreatine phosphate. This suggests that cyclocreatine phosphate is effectively replacing phosphocreatine in the brain and reversing the metabolic deficits, which results in cognitive normalization.

Mitochondrial CK is thought to modulate mitochondrial respiration by shifting the mitochondria's sensitivity to $\mathrm{ADP}$ (38). Brain mitochondria are essential for energy metabolism and normal cellular function. In CNS, the creatine/phosphocreatine/CK system is involved in neurotransmitter release, membrane potential maintenance, $\mathrm{Ca}^{2+}$ homeostasis, and/or ion gradient restoration
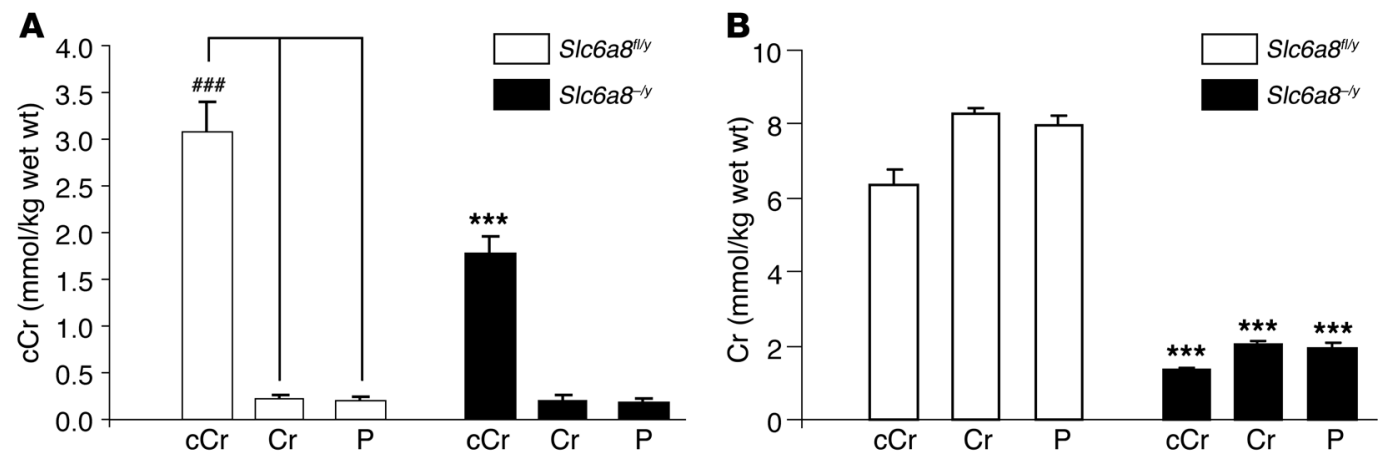

Figure 3

Increased cyclocreatine content in brain after cyclocreatine treatment. (A) Cyclocreatine (cCr) and (B) creatine $(\mathrm{Cr})$ content in brains of S/c6a8-ly mice ( $n=7$ [cyclocreatine]; 5 [creatine and placebo]) and S/c6a8 ${ }^{t / l y}$ littermate controls $(n=5$ per group) after 9 weeks of treatment, measured by biochemical assays. P, placebo. Data are mean \pm SEM. ${ }^{* \star *} P \leq 0.001$ vs. Slc6a8 ${ }^{t / l y}$; \#\#\# $P \leq 0.001$ as indicated by brackets. 

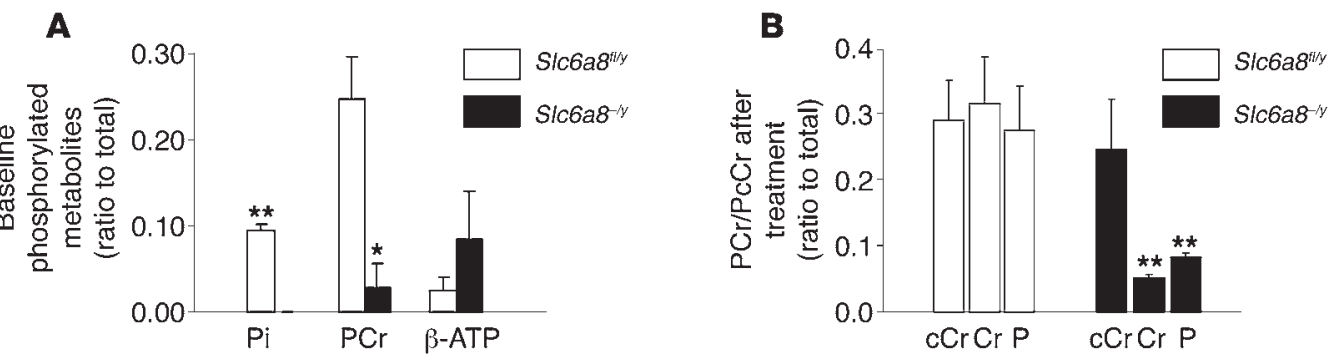

\section{Figure 4}

Phosphorylated metabolites in the brain, measured by ${ }^{31} \mathrm{P}-\mathrm{MRS}$. An indirect measure of the phosphate metabolites was determined by taking the peak height of the metabolite of interest and dividing by the sum of all the other phosphate metabolites. (A) Baseline measurements $(n=3$ per group) of inorganic phosphate (Pi), phosphocreatine (PCr), and $\beta$-adenosine triphosphate ( $\beta$-ATP). (B) Ratio of phosphocreatine plus phosphorylated cyclocreatine $(\mathrm{PcCr})$ to total phosphorylated metabolites after 9 weeks of treatment $(n=3$ per group). Data are mean \pm SEM. ${ }^{\star} P \leq 0.05,{ }^{* *} P \leq 0.01$ vs. S/c6a8 ${ }^{t / l y}$.

(1-3). One of the major energy-demanding activities of the CNS is action potentials. After depolarization of an action potential, which uses stored energy, the constitutive repolarization requires resynthesis of energy in the form of ATP and phosphocreatine. The ATP is used to reestablish the ionic gradients across the membrane. Action potentials often travel together along an axon as a train; the faster and longer the action potential train, the more energy the neuron uses (39). In Slc6a8- $y$ animals, it is possible that the ATP buffering is inadequate to meet the energy demands for certain action potential trains. Lack of phosphocreatine means the ATP concentration cannot be buffered, which could result in truncated or altered action potential trains with concomitant loss of message. Previous studies have suggested a relationship between impaired/improved cognitive function or hippocampal neurogenesis and changed brain energy metabolism that occurs upon consumption of a high-fat, low-carbohydrate diet $(40,41)$. Although we have not measured action potential trains or conduction velocities, our present studies demonstrate cognitive benefits manifest in Slc6a8 $8^{-1 y}$ mice after cyclocreatine treatment. This is consistent with other reports that creatine supplementation can improve cognitive performance parameters of healthy human subjects when brain creatine is increased $(42,43)$. It may be that with cyclocreatine phosphate, the ATP concentration was buffered; this was demonstrated by Woznicki et al., who showed that cyclocreatine phosphate indeed functions as an ATP buffer, like phosphocreatine, in the mouse brain in vivo (31).

The brain's dependence on the CK system has been previously demonstrated, to a certain extent, with knockout of the 2 CK isoenzymes expressed in brain, ubiquitous mitochondrial CK (UMTCK) and brain CK (CKBB) (44). These mice show cognitive deficits and abnormalities in the formation and maintenance of hippocampal fiber connections. The cause of the morphological changes in the absence of the CK is unclear. In our model, however, it seems apparent that the creatine/phosphocreatine/CK system plays a critical role in hippocampal function, which shows concomitant impairment with CRT knockout.

CRT therapies. Some groups - citing reports that the rodent brain has the enzymes to synthesize creatine $(5,4,26,27)$ - have attempted to treat patients with CRT deficiency by supplementing the synthesis precursors for creatine, but this approach did not succeed $(45,46)$. Even if creatine were synthesized in the brain, the synthesis enzymes appear to be in different cell types and unable to make enough creatine for normal function, because creatine was not detected or extremely low in patients with CRT deficiency and in Slc6a8 whole-body knockout mice (28). Thus, creatine is not entering or being made in the brain, or at least in the brain regions in which it is required. Importantly, our present study also showed no significant changes in brain creatine levels or in functional parameters in creatine-treated Slc6a8 $8^{-1 y}$ mice, which demonstrated that the CRT and creatine present in the animals' brains was inadequate to reverse the cognitive deficits.

Strikingly, cyclocreatine treatment normalized several of the cognitive parameters in adult $\operatorname{Slc} 6 a 8^{-/ y}$ mice, suggestive of not just a palliative improvement, but the return of substantial neurocognitive function. This is quite intriguing, given that the animals were adults when they started cyclocreatine treatment. It is also noteworthy that home cage activity did not significantly change, an observation that requires further investigation.

Cyclocreatine treatment. CRT deficiency is caused by a mutation of CRT, but it is also a disease of the 2 CKs. In the absence of its substrate, mitochondrial CK can crystallize (47) and lead to mitochondrial paracrystalline inclusions and concomitant pathology. Therefore, any treatment of CRT deficiency needs to address CRT, UMTCK, and CKBB in the cytosol. Cyclocreatine is known to interact with both of the CKs, and our present observations suggest that it effectively bypasses the transporter, making it an ideal drug to treat the disease.

Cyclocreatine was first synthesized by Kenyon and colleagues in 1971 (48). It was then evaluated for its biochemical properties in vitro and in vivo by Walker and others $(29,31)$. These investigators revealed that cyclocreatine is the most kinetically similar analog of creatine in vitro, with $V_{\max }$ approaching that of creatine itself (relative $V_{\max }, 90$ and $100 \mathrm{nmol} / \mathrm{s} ; K_{m}, 25$ and $5 \mathrm{mM}$, for cyclocreatine and creatine, respectively; ref. 29).

In mice fed cyclocreatine orally, the drug has been shown to be taken up by brains, be phosphorylated to cyclocreatine phosphate, and buffer ATP in vivo (31). These authors also demonstrated that maximal value for phosphorylation in the mouse brain is markedly higher for cyclocreatine than for the natural phosphagen, phosphocreatine. When mice were fed a cyclocreatine-containing diet, $98 \%$ of cyclocreatine observed in the brain was in the form of cyclocreatine phosphate, whereas $70 \%$ of creatine was phosphocreatine, a reflection of a distinct $K_{e q}$ for the compounds.

Chemically, our present data demonstrated 2 things: (a) accumulation of cyclocreatine in the brain was slower in Slc6a8-1y than in Slc6a $8^{f l y}$ mice, likely due to lack of CRT; and (b) cyclocreatine 
A

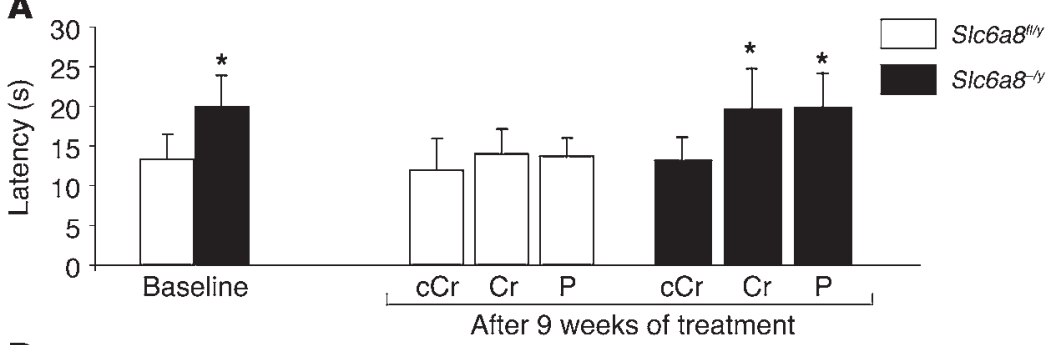

B

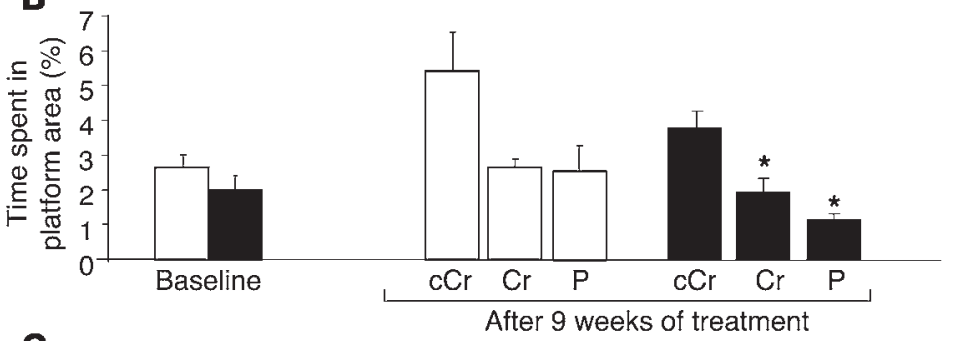

C

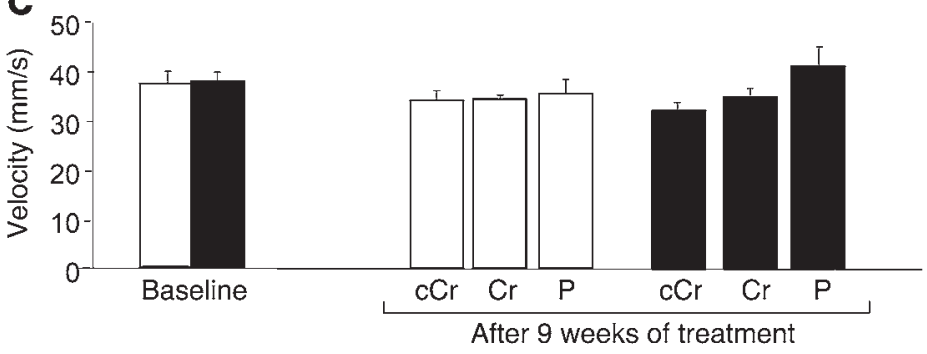

Figure 5

Improved spatial learning and memory in S/c6a8 ${ }^{-/ y}$ mice after cyclocreatine treatment. (A) Latency to hidden platform in trials, (B) percentage of time spent in platform area in probe trial, (C) and velocity of swimming in platform area in Morris water maze probe trial for S/c6a8 $8^{-/ y}(n=7$ [cyclocreatine]; 5 [creatine and placebo]) and S/c6a8fl/y $(n=5$ per group) mice before and after 9 weeks of treatment. Data are mean \pm SEM. ${ }^{*} P \leq 0.05$ vs. Slc6a8 ${ }^{t / l y}$. we believe that this can be monitored and mitigated, should such compilations arise in patients with CRT deficiency.

Future studies on cyclocreatine are required to determine the timing of the treatment and at what age it should be administered. Because cyclocreatine phosphate has a half-life of 17-28 days in the mouse brain in vivo (50), daily dosing may not be needed. The doses to be used in humans and the target cyclocreatine phosphate concentrations in the brain are also yet to be determined.

A word of caution concerning future clinical studies. The cyclocreatine we obtained was cGMP grade, used in the previous clinical studies and highly pure. A quick Internet search showed that cyclocreatine is available for sale, but at $98 \%$ and $99 \%$ pure. As the manufacture of cyclocreatine involves cyano compounds (30), it is possible that the impurities in reagent-grade cyclocreatine may be cyanohydrins or other toxins. Moreover, apocyclocreatine was marketed on one Internet site as cyclocreatine. Therefore, any human studies using cyclocreatine must be performed with great care using high-quality cyclocreatine. Patients with CRT deficiency and their families are not advised to try cyclocreatine treatment without consulting their physicians and ensuring that FDA drug safety standards for such treatments are met.

Conclusion. Our present findings showed that Slc6a8 $8^{-/ y}$ mice demonstrated the clinical manifestations of human CRT deficiency and were successfully treated by cyclocreatine. Further studies using these mice to assess pharmacodynamics, pharmacokinetics, and dose ranging are needed to better guide future clinical trials. entered the Slc6a8 $8^{-1 y}$ brain and was phosphorylated at levels similar to those in $\mathrm{Slc} 6 \mathrm{a} 8^{f / y}$ mice. One possible reason why cyclocreatine was taken up by the brains of Slc6a $68^{-/ y}$ mice is that cyclocreatine is a nearly planar 5-membered ring. Although our studies cannot definitively prove how or where cyclocreatine entered the brain in our Slc6a8 $8^{-1 y}$ model, they demonstrated that it was in fact entering and had a therapeutic effect.

Walker and colleagues also showed that in mice fed a diet containing large amounts of cyclocreatine, intraperitoneally inoculated Ehrlich ascites tumor cells grew more slowly than did those in mice fed a control diet (49). Studies followed concerning the effects of cyclocreatine on proliferation of various cancer cells, in vitro and in vivo, but did not lead to an approved drug. Reinforcing the possibility that cyclocreatine may be used to treat patients with CRT deficiency is the fact that it has already been given to humans; thus, the manufacture and toxicology have been established $(32,33)$. Using a repurposed drug may prove a faster and more effective method of getting the treatment to patients. Some side effects have been reported for cyclocreatine in humans $(1,32,33)$; we believe these can be mitigated with various monitoring strategies, such as assaying for cyclocreatine in the hair to monitor compliance or excess accumulation (Supplemental Figure 4). In human studies, hypoglycemia was reported when cyclocreatine was administered intravenously (1);

\section{Methods}

Materials. B. Tsao-Nivaggioli (Avicena Group, Palo Alto, California, USA) provided the cGMP-grade cyclocreatine used for this study. All other chemicals were reagent grade.

Generation of Slc6a8 $8^{-1 y}$ mice. A Cre-lox system (51) was used to generate a conditional Slc6a8 knockout in the brain. We first generated Slc6a8 floxed mice. Homologous recombination in C57BL/6N cells was carried out by transfecting a targeting vector containing a loxP site within intron 1 and a positive selection cassette containing the neomycin phosphotransferase gene (neo) flanked by Frt sites and the second loxP site within intron 4 (Figure 2A). Neomycin-resistant ES cell clones were screened for homologous recombination by PCR, followed by Southern blot analysis of ES cell genomic DNA using probes located outside the $5^{\prime}$ and $3^{\prime}$ homology arms. Correctly targeted ES cell clones were injected into MF-1 blastocysts. Male chimeras were crossed with C57BL/6J females to produce N1F0 offspring, which was confirmed by Southern blot and PCR analysis. The conditional allele was generated by breeding the heterozygous mice to a germline Flp deleter strain (Jackson Laboratory) to delete the neo cassette, leaving a single loxP and Frt sites in intron 4 . The resulting mice were further bred with C57BL/6J females to be free of flpase. We then crossed Slc6a $8^{f / f l}$ female mice with male mice (C57BL/6J) expressing a Cre recombinase driven by the CamkII $\alpha$ promoter in the brain (52) to generate $S l c 6 a 8^{-1 y}$ mice and Slc6a $8^{f / y}$ littermate controls. We chose this Cre construct because it drives expression throughout the mouse brain, but shows particularly dramatic 


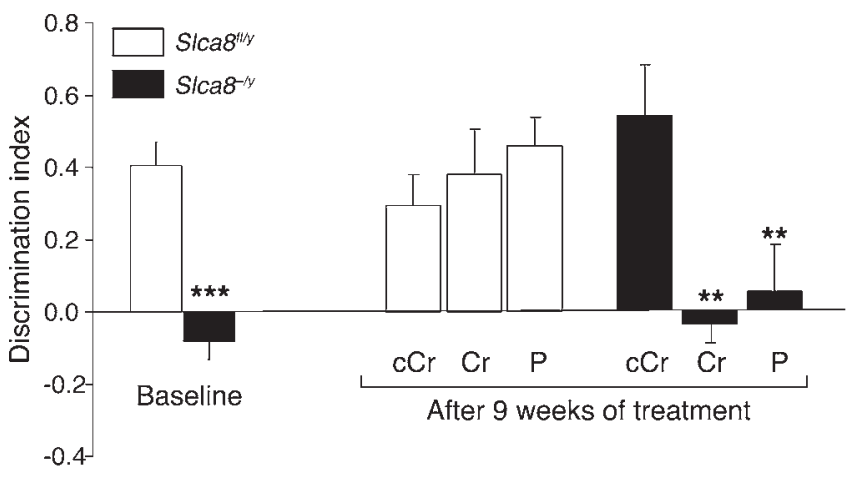

\section{Figure 6}

Improved object recognition memory in S/c6a8-/y mice after cyclocreatine treatment. Novel object recognition tests were conducted 3 hours after familiarization in S/c6a8 ${ }^{-1 y}$ ( $n=7$ [cyclocreatine]; 5 [creatine and placebo]) and S/c6a8 $8^{f / y}$ ( $n=5$ per group) mice before and after 9 weeks of treatment. The discrimination index was calculated as the difference between new and familiar object exploration times divided by total time spent in object zones. Data are mean \pm SEM. ${ }^{* \star} P \leq 0.01$, ${ }^{* \star *} P \leq 0.001$ vs. S/c6a8 ${ }^{\text {flly }}$.

expression in the hippocampus and cortex, areas controlling cognitive function, which is an important aspect of the human phenotype. It is also known that Slc6a8 is highly expressed in that area in mice (53). We did not observe problems with the floxed mice, so we used Slc6a $8^{f / y}$ animals as control littermates. This minimizes the influence of genetic background on the observed phenotype. A total of 29 Slc6a8 $-/ y$ mice and 28 male Slc6a8f/y controls were used in this study. At 6 months of age, baseline assessment was performed for all mice. To assess the efficacy of cyclocreatine treatment, 17 of the $29 \operatorname{Slc} 6 a 8^{-/ y}$ mice and 15 of the $28 \mathrm{Slc} 6 a 8^{f / y}$ controls were further used for 9 weeks of treatment.

Experimental design. Mice were maintained on an ad libitum standard pelleted diet (Teklad irradiated standard diets; Harlan animal research laboratory) and on ad libitum water intake with 12-hour dark/light cycles in $70^{\circ} \mathrm{F} \pm 2^{\circ} \mathrm{F}$ through the study. At the conclusion of the study, mice were analyzed for Slc6a 8 mRNA levels. Other tests - such as baseline values for working and reference memory, novel object recognition, Morris water maze, body composition, home cage locomotor activity, rotarod, hanging wire grip, and beam walk tests - were done before and after treatment. At 12 months of age, $\operatorname{Slc} 6 a 8^{-/ y}$ and $\operatorname{Slc} 6 a 8^{f / y}$ mice were randomly assigned to groups and started on 1 of 3 treatments for 9 weeks: (a) cyclocreatine $(n=7$ [Slc6a8 $\left.\left.8^{-1 y}\right] ; 5\left[S l c 6 a 8^{f / y}\right]\right),(\mathrm{b})$ creatine ( $n=5$ per group), and (c) maltodextrin as placebo ( $n=5$ per group). Each treatment compound was supplemented in the drinking water, and the concentration was adjusted to deliver $0.28 \mathrm{mg} / \mathrm{g}$ body weight $/ \mathrm{d}$. This is a standard creatine dose for human subjects $(20 \mathrm{~g} / 70 \mathrm{~kg}$ body weight/d), intended to induce maximum creatine or phosphocreatine concentrations inside the body. Body weight and water and food intake volumes were monitored every other day throughout the treatment period. After 9 weeks of treatment, each parameter was evaluated and compared with baseline values or between groups.

Genotyping. Genotyping of the conditional allele was performed by PCR with primers that flank the position of the loxP-Frt insertion with genomic DNA from mouse tail and brain templates (VS747 in intron 4, 5' -AGGTCCAGACAGTAACTACCCTTC-3'; VS584 in intron 4, 5' -TGGGTTTGCAGCTTGGTGTTATTGC-3'; Pnew in intron 1, 5' -TCCTACACCAATACCCCCATAAGC- $3^{\prime}$ ) under the following conditions: 40 cycles of a reaction consisting of 30 seconds of denaturation at $94^{\circ} \mathrm{C}, 30$ seconds of annealing at $58^{\circ} \mathrm{C}$, and 1 minute of elongation at $72^{\circ} \mathrm{C}$, followed by a final extension for 10 minutes at $72^{\circ} \mathrm{C}$. The expected product sizes were $422 \mathrm{bp}$ for the WT allele, $548 \mathrm{bp}$ for the floxed allele, and $346 \mathrm{bp}$ for the knockout allele. PCR for Cre recombinase expression was performed with genomic DNA from mouse tail templates (Cam k1, 5'-GGTTCTCCGTTTGCACTCAGGA-3'; Cam k2, 5'-CCTGTTGTTCAGCTTGCACCAG-3'; Cam k5, 5 '-CTGCATGCACGGGACAGCTCT- $3^{\prime}$ ) under the following conditions: 30 cycles of a reaction consisting of 30 seconds of denaturation at $94^{\circ} \mathrm{C}$, 30 seconds of annealing at $67^{\circ} \mathrm{C}$, and 1 minute of elongation at $72^{\circ} \mathrm{C}$, followed by a final extension for 10 minutes at $72^{\circ} \mathrm{C}$. The expected product sizes were $350 \mathrm{bp}$ for Cre recombinase and $300 \mathrm{bp}$ for the internal control. PCR products were separated by electrophoresis on a $1.5 \%$ agarose gel and visualized by ethidium bromide staining; images were taken with a Universal Hood II (Bio-Rad Laboratories).

Semiquantified RT-PCR. Total RNA was extracted from brain tissues of Slc6a8 $8^{-1 y}$ and $S l c 6 a 8^{f / y}$ mice at 6 months of age using TRIzOL reagent (Invitrogen) according to the manufacturer's instruction and was quantified by determination of absorbance at A260. Then, total RNA was treated with RNase-free DNase (Ambion). RT priming with oligo (dT) primers (Invitrogen) was performed to generate cDNAs from $1 \mu \mathrm{g}$ total RNA using Superscript II (Invitrogen) following the manufacturer's instructions. Equal amounts of cDNA from all samples were subjected to PCR. PCR primer pairs were as follows: Slc6a8 forward, 5 '-CCATGAAGACTGTGCCAATG-3'; Slc6a8 reverse, 5'-CCCCTTCCACACACAGAAGT-3'; Actb forward, 5'-GTGGGCCGCCCTAGGCACCAG-3'; Actb reverse, $5^{\prime}$-CTCTTTGATGTCACGCACGATTTC-3'. Reactions were performed in $25 \mu \mathrm{l}$ total volume with $25 \mathrm{pM}$ of each primer. Amplification conditions were as follows: $95^{\circ} \mathrm{C}$ for 10 minutes, followed by 28 or 25 cycles (for Slc $6 a 8$ or $A c t b$, respectively) of $95^{\circ} \mathrm{C}$ for 30 seconds, $60^{\circ} \mathrm{C}$ for 30 seconds, and $72^{\circ} \mathrm{C}$ for 30 seconds. The expected product size was $202 \mathrm{bp}$. Amplified fragments were separated by electrophoresis on $2 \%$ agarose gels and visualized by ethidium bromide staining. The intensity of each band was measured by Scion Image (Scion Corp.), and the intensity of Slc6a8 was expressed relative to that of Actb.

Cyclocreatine and creatine assay. Animals were deeply anesthetized with $1 \%-2 \%$ isoflurane delivered with oxygen. Whole blood was harvested with a 1-ml syringe and 27-gauge, 0.625 -inch needle from the heart and centrifuged at 3,000 $\mathrm{g}$ for 20 minutes; serum was subsequently placed in Eppendorf tubes. Brain, liver, heart, kidney, lung, bladder, and soleus and gastrocnemius muscles were rapidly removed and frozen in liquid nitrogen. Urine and hair samples were also collected. The samples were each dropped into $250 \mu \mathrm{l}$ boiling water and boiled for 20 minutes to remove protein and lyse cells. The total creatine content of the protein-free extract was assayed using the fluorometric method of Conn (54). Total cyclocreatine content of brain and hair was assayed using the method of Griffith (55). All chemicals were obtained from Sigma-Aldrich unless otherwise stated.

In vivo MRS. All data were collected on a Bruker BioSpec $7 \mathrm{~T}$ system (Bruker BioSpec 70/30) equipped with $400 \mathrm{mT} / \mathrm{m}$ actively shielded gradients. In total, 6 mice were used at baseline assessment, and 18 mice after 9 weeks of treatment. Mice were anesthetized by $1 \%-2 \%$ isoflurane delivered in air, and the respiration rate was maintained at $60-100$ breaths per minute. Core temperature was maintained at $37^{\circ} \mathrm{C}$ by warm air circulated through the magnet bore. All animals' brains were scanned with a custombuilt radio frequency coil. T2-weighted axial and sagittal localizer images were acquired with a fast-spin echo sequence. A proton double-spin echo sequence was used to shim on a voxel approximately $6 \mathrm{~mm} \times 4 \mathrm{~mm} \times 6 \mathrm{~mm}$, covering most of the brain. The water proton line width averaged about $17 \mathrm{~Hz}$. After shimming, ${ }^{31} \mathrm{P}$ data were acquired with an ISIS sequence from the same voxel using a 4-second repetition time, 2,048 complex points, $8,000 \mathrm{~Hz}$ spectral width, and 4 repetitions of 480 averages each. Total phosphorus acquisition time was 2 hours. Individual metabolites 
A

Normal brain

\begin{tabular}{|lr|}
\hline $\begin{array}{l}\text { ATPases at membranes, etc. } \\
\text { Energy consumption }\end{array}$ & Brain cell membrane \\
\hline
\end{tabular}

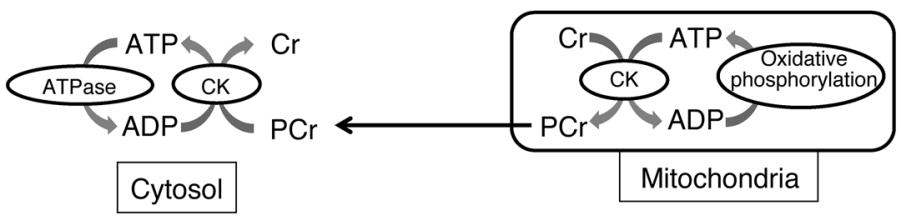

Cytosolic CK maintains substrate concentrations; PcCr "buffers" ATP concentrations and ensures a constant energy supply to the cell.

\section{Figure 7}

Creatine and cyclocreatine in brain function. (A) The creatine/CK system is essential for shuttling energy from sites of energy production to sites of energy use. Creatine and phosphocreatine can modulate energy metabolism at the mitochondria and glycolytic pathways. When creatine is absent, energy supply can be insufficient or slow during energy demands. Having cyclocreatine and phospholylated cyclocreatine keeps ATP levels more constant and decreases pathophysiological consequences. (B) In contrast to the transport and use of creatine by the normal brain, with CRT deficiency, creatine cannot enter the brain, resulting in poor speech and cognition. In the cyclocreatine-treated CRT deficiency brain, cyclocreatine enters brain cells and works with the cell's metabolism to improve speech and cognition.

B
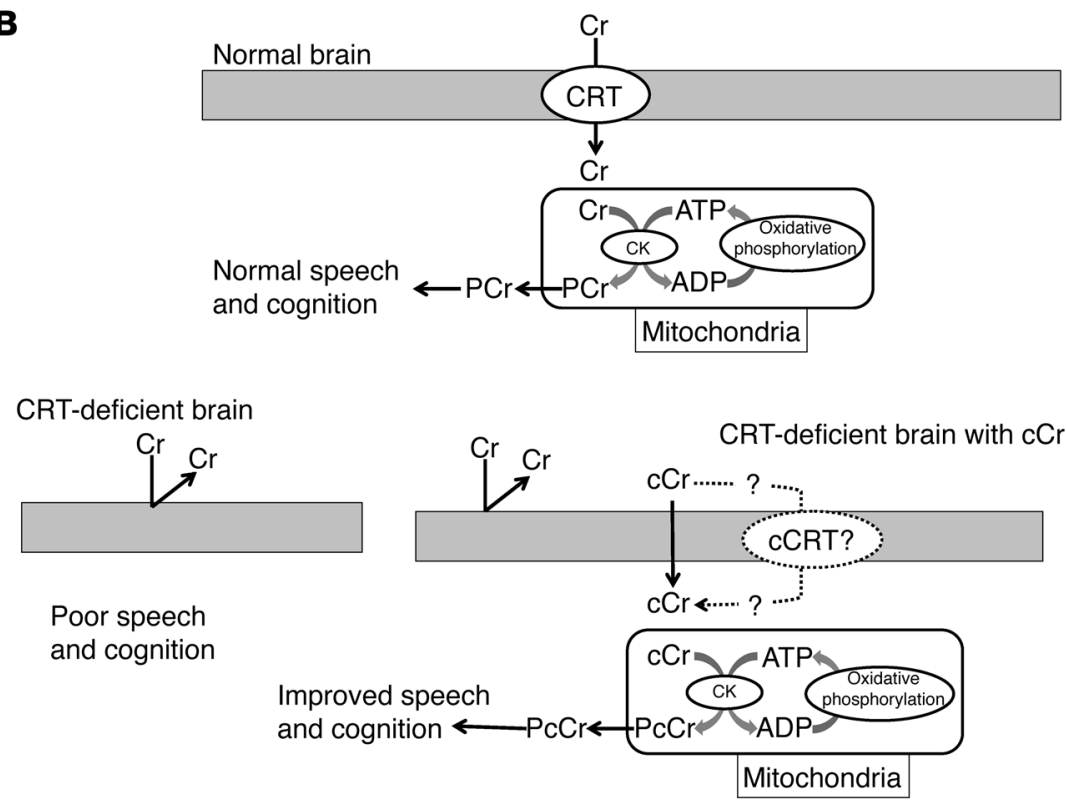

were identified by chemical shift. Ratios of metabolites to total phosphorus were calculated by comparing the total peak amplitude of all phosphorylated metabolites with the individual peak heights. Metabolite peak heights were averaged and reported.

Morris water maze. Before and after 9 weeks of treatment, a total of 32 mice were subjected to Morris water maze testing, a hippocampaldependent task of spatial learning and memory. The maze consisted of a circular fiberglass pool $(122 \mathrm{~cm}$ diameter, $75 \mathrm{~cm}$ high; Rowland Fiberglass Inc.) filled with water $\left(18 \pm 1^{\circ} \mathrm{C}, 43 \mathrm{~cm}\right.$ deep $)$. A clear glass platform $(10.5 \mathrm{~cm} \times 10.5 \mathrm{~cm}$ square) was submerged $1 \mathrm{~cm}$ below the water surface. The pool was situated in a room containing extramaze cues $(42-\mathrm{cm} \times 76-\mathrm{cm}$ posters printed with contrasting patterns and shapes) that provide specific visual reference points for locating the submerged platform. A video camera mounted to the ceiling, directly above the center of the pool, was used for recording the probe trial. The recording was digitized by a computer and analyzed using CleverSystem Topscan software (Cleversys) for path analysis (distance traveled and percentage of time in the target platform area). Each mouse received 3 trials in the water maze on each of 5 days. The submerged platform remained in one quadrant of the pool throughout all trials, and latency to find the platform was recorded. If the mouse failed to reach the platform within 60 seconds, the trial was terminated, and the mouse was guided onto the platform for 5 seconds. On the sixth day, each mouse received a final 60 -second probe trial in which the platform was removed from the pool.

Radial maze. An 8-arm radial maze was used to test spatial working and reference memory at baseline with a total of 32 mice $\left(n=17\right.$ [Slc $\left.6 a 8^{-1 y}\right] ; 15$ $\left.\left[S l c 6 a 8^{f / y}\right]\right)$. The maze consisted of an octagonal central platform $(51.5 \mathrm{~cm}$ in diameter) with 8 radial arms ( $61 \mathrm{~cm}$ long, $12 \mathrm{~cm}$ wide, $10 \mathrm{~cm}$ high) extending outward (Lafayette Instrument Co.). The maze was elevated $70.5 \mathrm{~cm}$ above the floor in a room containing many extramaze visual cues. Mice must use these visual stimuli to navigate the maze, which lacked intramaze, nonspatial cues for navigation. First, a food deprivation schedule was carried out to reduce animals' weight to $85 \%$ of baseline. During the entire training and test periods, water was available ad libitum. Next, an acclimation trial was conducted. On days 1 and 2, food pellets were placed near the end of all arms. From day 3, food pellets were located only in arms 3, 5, 7, and 8; the 
remaining 4 arms were empty. Mice received 1 or 2 training trials per day for 22 trials, and then were tested using reversed baited arms (food pellets in arms 1, 2, 4, and 6 only) for 28 trials, for a total of 50 trials. At the beginning of each trial, mice were placed in the central platform, then allowed to explore the maze. Trials were completed when the 4 food pellets were eaten or 15 minutes had elapsed. Arm entries for each mouse were recorded by an investigator. The total number of entries into unbaited arms was tabulated as an index of reference memory error, and the number of reentries into previously baited arms was used as an index of working memory error.

Novel object recognition. Before and after 9 weeks of treatment, the novel object recognition task was conducted in a Plexiglas open-field apparatus $(60 \mathrm{~cm} \times 50 \mathrm{~cm} \times 21 \mathrm{~cm}$ high) to test short-term recognition. Mice were individually habituated to the open-field apparatus with no objects in the cage for 5 minutes at a time on 3 consecutive days. On the fourth day, 2 identical objects (50-ml falcon tubes, $11 \mathrm{~cm}$ high, $3.5 \mathrm{~cm}$ diameter, covered with yellow tape) were placed symmetrically $12 \mathrm{~cm}$ away from the wall. The mouse was placed near the wall at equal distance from both objects and observed for 5 minutes. A second 5-minute trial was done 3 hours later, in which one of the familiar objects was replaced by a novel one (tube $4 \mathrm{~cm}$ in diameter, covered with red tape). We defined exploration zones around the objects (10 cm diameter), and time spent inside the zones was used as an index of object exploration. The discrimination index was calculated by dividing the difference between exploration times of the new object and the familiar object by the total time spent in object zones.

Body composition analysis. Total lean tissue, fat tissue, and water of the 32 total Slc6a8 $8^{-/ y}$ and Slc6a8 $8^{f / y}$ mice was determined by MRI (56) before and after 9 weeks of treatment. After system calibration, an unanesthetized mouse was weighed, placed in the restraint tube, and inserted into the Echo MRI whole-body composition analyzer (EchoMedical Systems) for 45 seconds. Fat mass and lean body mass were determined.

Home cage locomotor activity. We measured the locomotor activity expressed by each animal in its home cage before and after 9 weeks of treatment. This allowed us to capture general locomotor activity, unrelated to the animals' activity in a novel, anxiogenic environment. The cage rack frame (Lafayette Instrument Co.) equipped with infrared photobeams was placed around each animal's standard shoebox home cage. Infrared photobeam interruption sensors ( $7 \mathrm{X}$ and $15 \mathrm{Y}$ ) mounted in the frame detected movement, which was recorded and analyzed using HMM100 Motor Monitor software (Lafayette Instrument Co.). Vertical and horizontal activity within the home cage was recorded for 48 hours, and events were collapsed into 60-minute bins. In order to discern short- and long-term activityrelated circadian rhythms, results were expressed as the average number of beam interruptions per group per hour.

Rotarod. The rotarod test of motor coordination and motor learning was performed before and after 9 weeks of treatment. On day 1 , mice were placed on a stationary rod $(3.2 \mathrm{~cm}$ diameter) of the apparatus (Type ENV-576M; Med associates) for 30 seconds. Daily training trials were then administered for the next 7 consecutive days: mice were placed on the rod at increasing speeds, from 16 to $32 \mathrm{rpm}$, for up to 2 minutes. On day 9 , mice were placed on the stationary rod at maximum speed ( $32 \mathrm{rpm}$ ). The duration in seconds until the animal fell from the rod was recorded as a measure of motor coordination; cutoff time was 120 seconds.

Hanging wire grip. Before and after 9 weeks of treatment, the hanging wire grip test was performed by placing a mouse on a wire net $(2.5-\mathrm{cm} \times 2.5-\mathrm{cm}$ grid, $30 \mathrm{~cm}^{2}$ wire), then turning the net upside-down at approximately $50 \mathrm{~cm}$ above the cage floor to prevent the animal from easily climbing down. The elapsed time until the animal fell was recorded. Tests consisted of 3 trials with 30-second intervals; cutoff time was 540 seconds.

Beam walk. The beam walk is a test of complex motor coordination. Before and after 9 weeks of treatment, animals were trained to ambulate across the beam ( $1 \mathrm{~m}$ long, $9 \mathrm{~mm}$ diameter) to a $14-\mathrm{cm}^{2}$ platform for 7 consecutive days. On day 8 , mice were placed on the beam $50 \mathrm{~cm}$ from the platform, and latency to reach the platform was measured. Missed steps off of the beam were also recorded.

Statistics. Data are expressed as mean \pm SEM. Statistical significance of mean differences for each parameter was determined by 2-tailed Student's $t$ test; by ANOVA followed by post-hoc Tukey test (treatment group as between-subject factor); or by repeated-measures ANOVA followed by post-hoc Bonferroni test for multiple comparisons (treatment group and treatment timing as between- and within-subject factors). A $P$ value less than 0.05 was considered significant.

Study approval. The experimental procedures performed herein were in compliance with the NIH Guide for the Care and Use of Laboratory Animals and were approved by the University of Cincinnati Institutional Animal Care and Use Committee.

\section{Acknowledgments}

The authors thank Akiko Kuma (Tokyo Medical and Dental University, Tokyo, Japan) for her scientific advice. This work was supported by funding from the NIH (grant no. NS049172). T. Daikoku was supported by Cincinnati Children's Hospital Medical Center (Perinatal Institute Pilot/Feasibility Grant).

Received for publication February 15, 2012, and accepted in revised form May 23, 2012.

Address correspondence to: Joseph F. Clark, University of Cincinnati, 231 Albert Sabin Way, MSB Building Room 1055B, Cincinnati, Ohio 45267-0536, USA. Phone: 513.558.7085; Fax: 513.558.7009; E-mail: joseph.clark@uc.edu.
1. Wyss M, Kaddurah-Daouk R. Creatine and creatinine metabolism. Physiol Rev. 2000;80(3):1107-1213.

2. Snow RJ, Murphy RM. Creatine and the creatine transporter: a review. Mol Cell Biochem. 2001; 224(1-2):169-181.

3. Christie DL. Functional insights into the creatine transporter. In: Salomons GS, Wyss M, eds. Creatine and Creatine Kinase in Health and Disease. Dordrecht, The Netherlands: Springer; 2007:99-118.

4. Braissant O, Henry H, Villard AM, Speer O, Wallimann T, Bachmann C. Creatine synthesis and transport during rat embryogenesis: spatiotemporal expression of AGAT, GAMT and CT1. BMC Dev Biol. 2005;5:9.

5. Braissant O, Henry H, Loup M, Eilers B, Bachmann C. Endogenous synthesis and transport of creatine in the rat brain: an in situ hybridization study. Mol Brain Res. 2001;86(1-2):193-201.
6. Ohtsuki S, et al. The blood-brain barrier creatine transporter is a major pathway for supplying creatine to the brain. J Cereb Blood Flow Metab. 2002; 22(11):1327-1335.

7. Tachikawa M, Fukaya M, Terasaki T, Ohtsuki S, Watanabe M. Distinct cellular expressions of creatine synthetic enzyme GAMT and creatine kinases uCK-Mi and CK-B suggest a novel neuron-glial relationship for brain energy homeostasis. Eur J Neurosci. 2004;20(1):144-160.

8. Pyne-Geithman GJ, et al. Presence of normal creatine in the muscle of a patient with a mutation in the creatine transporter: a case study. Mol Cell Biochem. 2004;262(1-2):35-39.

9. DeGrauw TJ, Cecil KM, Byars AW, Salomons GS, Ball WS, Jakobs C. The clinical syndrome of creatine transporter deficiency. Mol Cell Biochem. 2003; 244(1-2):45-48.
10. Póo-Argüelles P, et al. X-Linked creatine transporter deficiency in two patients with severe mental retardation and autism. J Inherit Metab Dis. 2006; 29(1):220-223.

11. Sempere A, et al. Creatine transporter deficiency in two adult patients with static encephalopathy [published online ahead of print March 25, 2009]. J Inherit Metab Dis. doi:10.1007/s10545-009-1083-2.

12. Mancini GM, et al. Two novel mutations in SLC6A8 cause creatine transporter defect and distinctive $\mathrm{X}$-linked mental retardation in two unrelated Dutch families. Am J Med Genet A. 2005; 132A(3):288-295.

13. Mercimek-Mahmutoglu S, et al. GAMT deficiency: features, treatment, and outcome in an inborn error of creatine synthesis. Neurology. 2006; 67(3):480-484.

14. Bianchi MC, Tosetti M, Fornai F, Cipriani P, De 
Vito G, Canapicchi R. Reversible brain creatine deficiency in two sisters with normal blood creatine level. Ann Neurol. 2000;47(4):511-513.

15. Battini R, et al. Creatine depletion in a new case with AGAT deficiency: clinical and genetic study in a large pedigree. Mol Genet Metab. 2002;77(4):326-331.

16. Cecil KM, et al. Irreversible brain creatine deficiency with elevated serum and urine creatine: a creatine transporter defect? Ann Neurol. 2001;49(3):401-404.

17. Newmeyer A, Cecil KM, Schapiro M, Clark JF, Degrauw TJ. Incidence of brain creatine transporter deficiency in males with developmental delay referred for brain magnetic resonance imaging. J Dev Behav Pediatr. 2005;26(4):276-282.

18. Newmeyer A, deGrauw T, Clark J, Chuck G, Salomons G. Screening of male patients with autism spectrum disorder for creatine transporter deficiency. Neuropediatrics. 2007;38(6):310-312

19. Rosenberg EH, et al. High prevalence of SLC6A8 deficiency in X-linked mental retardation. $A m$ Hum Genet. 2004;75(1):97-105.

20. Puusepp H, et al. The screening of SLC6A8 deficiency among Estonian families with X-linked mental retardation [published online ahead of print January 10, 2009]. J Inherit Metab Dis. doi:10.1007/s10545-008-1063-y.

21. Schulze A, et al. Creatine deficiency syndrome caused by guanidinoacetate methyltransferase deficiency: diagnostic tools or a new inborn error of metabolism. J Pediatr. 1997;131(4):626-631.

22. Ensenauer R, et al. Guanidinoacetate methyltransferase deficiency: differences of creatine uptake in human brain and muscle. Mol Genet Metab. 2004; 82(3):208-213.

23. Stöckler-Ipsiroglu S, Salomons GS. Creatine deficiency syndromes. In: Fernandes J, Saudubray JM, van den Berghe G, eds. Inborn Metabolic Diseases. Heidelberg, Germany: Springer Verlag; 2006:211-217.

24. Bizzi A, et al. X-linked creatine deficiency syndrome: a novel mutation in creatine transporter gene SLC6A8. Ann Neurol. 2002;52(2):227-231.

25. Arias A, et al. Creatine transporter deficiency: prevalence among patients with mental retardation and pitfalls in metabolite screening. Clin Biochem. 2007;40(16-17):1328-1331

26. Ireland Z, Russell AP, Wallimann T, Walker DW, Snow R. Developmental changes in the expression of creatine synthesizing enzymes and creatine transporter in a precocial rodent, the spiny mouse. BMC Dev Biol. 2009;9:39.

27. Braissant O, Béard E, Torrent C, Henry H. Dissociation of AGAT, GAMT and SLC6A8 in CNS: relevance to creatine deficiency syndromes. Neurobiol Dis. 2010;37(2):423-433.

28. Skelton MR, et al. Creatine transporter (CRT;
Slc6a8) knockout mice as a model of human CRT deficiency. PLoS One. 2011;6(1):e16187.

29. McLaughlin AC, Cohn M. Specificity of creatine kinase for guanidine substrates. J Biol Chem. 1972; 247(13):4382-4388

30. Boehm EA, Radda GK, Tomlin H, Clark JF. The utilisation of creatine and its analogues by cytosolic and mitochondrial creatine kinase. Biochim Biophys Acta. 1996;1274(3):119-128.

31. Woznicki DT, Walker JB. Formation of a supplemental long time-constant reservoir of high energy phosphate by brain in vivo and in vitro and its reversible depletion by potassium depolarization. J Neurochem. 1979;33(1):75-80.

32. Hoosein NM, Martin KJ, Abdul M, Logothetis CJ, Kaddurah-Daouk R. Antiproliferative effects of cyclocreatine on human prostatic carcinoma cells. Anticancer Res. 1995:15(4):1339-1342.

33. Teicher BA, Menon K, Northey D, Liu J, Kufe DW, Kaddurah-Daouk R. Cyclocreatine in cancer chemotherapy. Cancer Chemother Pharmacol. 1995; 35(5):411-416

34. LoPresti P, Cohn M. Direct determination of creatine kinase equilibrium constants with creatine or cyclocreatine substrate. Biochim Biophys Acta. 1989; 998(3):317-320.

35. Almeida LS, et al. Creatine and guanidinoacetate: diagnostic markers for inborn errors in creatine biosynthesis and transport. Mol Genet Metab. 2004; 82(3):214-219

36. Verhoeven NM, Salomons GS, Jakobs C. Laboratory diagnosis of defects of creatine biosynthesis and transport. Clin Chim Acta. 2005;361(1-2):1-9.

37. Braissant $\mathrm{O}$. Creatine and guanidinoacetate transport at blood-brain and blood-cerebrospinal fluid barriers [published online ahead of print January 18, 2012]. J Inherit Metab Dis. doi:10.1007/s10545011-9433-2.

38. Walsh B, Tonkonogi M, Söderlund K, Hultman E, Saks V, Sahlin K. The role of phosphorylcreatine and creatine in the regulation of mitochondrial respiration in human skeletal muscle. J Physiol. 2001; 537(pt 3):971-978.

39. Stojikovic SS. Ion channels, transporters, and electrical signaling. In: Conn PM, ed. Neuroscience In Medicine. 3rd ed. New York, New York, USA: Humana Press; 2008:53-89.

40. Krikorian R, Shidler MD, Dangelo K, Couch SC, Benoit SC, Clegg DJ. Dietary ketosis enhances memory in mild cognitive impairment. Neurobiol Aging. 2012;33(2):425.e19-425.e27.

41. Park HR, Park M, Choi J, Park KY, Chung HY, Lee J. A high-fat diet impairs neurogenesis: involvement of lipid peroxidation and brain-derived neurotrophic factor. Neurosci Lett. 2010;482(3):235-239.

42. Rae C, Digney AL, McEwan SR, Bates TC. Oral creatine monohydrate supplementation improves brain performance: a double-blind, placebocontrolled, cross-over trial. Proc Biol Sci. 2003; 270(1529):2147-2150.

43. Watanabe A, Kato N, Kato T. Effects of creatine on mental fatigue and cerebral hemoglobin oxygenation. Neurosci Res. 2002;42(4):279-285.

44. Bürklen TS, et al. The creatine kinase/creatine connection to Alzheimer's disease: CK inactivation, APP-CK complexes, and focal creatine deposits. J Biomed Biotechnol. 2006;2006(3):35936.

45. Fons $\mathrm{C}$, et al. Arginine supplementation in four patients with X-linked creatine transporter defect. J Inherit Metab Dis. 2008;31(6):724-728.

46. Chilosi A, et al. Treatment with L-arginine improves neuropsychological disorders in a child with creatine transporter defect. Neurocase. 2008; 14(2):151-161.

47. Stadhouders AM, Jap PH, Winkler HP, Eppenberger HM, Wallimann T. Mitochondrial creatine kinase: a major constituent of pathological inclusions seen in mitochondrial myopathies. Proc Natl Acad Sci U S A. 1994;91(11):5089-5093.

48. Rowley GL, Greenleaf AL, Kenyon GL. On the specificity of creatine kinase; New glycocyamines and glycocyamine analogs related to creatine. $\mathrm{J} \mathrm{Am}$ Chemical Soc. 1971;93(12):5542-5551.

49. Annesley TM, Walker JB. Formation and utilization of novel high energy phosphate reservoirs in Ehrlich ascites tumor cells. J Biol Chem. 1978; 253(22):8120-8125.

50. Woznicki DT, Walker JB. Utilization of cyclocreatine phosphate, an analogue of creatine phosphate, by mouse brain during ischemia and its sparing action on brain energy reserves. J Neurochem. 1980;34(5):1247-1253.

51 . Sauer B. Inducible gene targeting in mice using the Cre/lox system. Methods. 1998;14(4):381-392.

52. Casanova E, et al. A CamKIIalpha iCre BAC allows brain-specific gene inactivation. Genesis. 2001; 31(1):37-42.

53. Tachikawa M, et al. Expression and possible role of creatine transporter in the brain and at the bloodcerebrospinal fluid barrier as a transporting protein of guanidinoacetate, an endogenous convulsant. J Neurochem. 2008;107(3):768-778.

54. Conn RB Jr. Fluorometric determination of creatine. Clin Chem. 1960;6(6):537-548.

55. Griffith GR, Walkers JB. Accumulation of analog of phosphocreatine in muscle of chicks fed 1-carboxymethyl-2-iminoimidazolidine (cyclocreatine). J Biol Chem. 1976;251(7):2049-2054.

56. Taicher GZ, Tinsley FC, Reiderman A, Heiman ML. Quantitative magnetic resonance (QMR) method for bone and whole-body-composition analysis. Anal Bioanal Chem. 2010;377(6):990-1002. 